\title{
MODEL MATEMATIKA KESEIMBANGAN PASAR
}

\author{
Dede Ruslan \\ Fakultas Ekonomi, Universitas Negeri Medan \\ Jl. Williem Iskandar Ps. V Medan 20221, Telp. +6261-6613365 \\ Email: dras ruslan@yahoo.com
}

\begin{abstract}
The market is the place where the buyer and the seller are met in order to do various transactions that is based on the numbers of supply and demand. The supply and demand of any goods is affected by the supply and demand of other goods. The equilibrium the market can be overcome if the equilibrium of the price can be achieved. The model of the multi market that has been developed by Samuelson can be changed to homogeny differential equation with the use of stabilizing matrix that can verify that the price can move towards the stabilization of the market equilibrium
\end{abstract}

Key words: Marke Equilibrium,Stabilization

\section{PENDAHULUAN}

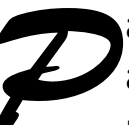
asar barang merupakan suatu tempat terjadinya permintaan dan penawaran atau transaksi atas suatu barang atau komoditas yang dilakukan oleh para pelaku pasar, yaitu pembeli dan penjual. Jika dalam suatu pasar tersebut lebih dari satu jenis komoditas yang saling berinteraksi satu sama lainnya maka kondisi tersebut dapat disebut sebagai pasar berganda atau multimarket. Pada pasar berganda permintaan dan penawaran suatu barag akan dipengaruhi oleh permintaan dan penawaran barang lainnya baik yang bersifat subsitusi, komplementer ataupun barang sejenis yang merupakan pesaingnya. Dengan demikian pasar berganda ini tentu berbeda dengan pasar yang terdiri dari satu barang saja.

Analisis kestabilan keseimbangan pasar berganda dinamik pertama kali dianalisis dalam kasus 2 komoditi oleh Leon Walms, kemudian dilanjutkan oleh Hisck untuk kasus $\mathrm{n}$ komoditas. Samuelson kemudian melakukan pendekatan baru dengan menganalisis kestabilan keseimbangan dalam bentuk sistem persamaan diferensial untuk kasus $n$ komoditas. Keseimbangan dalam pasar berganda akan tercapai jika untuk semua komoditas barang, berlaku hukum keseimbangan pasar yaitu bahwa permintan akan selalu sama dengan penawaran.

Interaksi antara permintaan dan penawaran tersebut menyebabkan adanya pergerakan harga. Harga akan menuju pada kondisi keseimbangan pasar, dimana harga yang diminta oleh pembeli akan sama dengan harga yang ditawarkan oleh penjual. Interaksi antara permintaan dan penawaran barang ini akan terus berlanjut 
dan harga akan terus bergerak menuju harga keseimbangan dan jika hal itu terjadi, maka harga keseimbangan stabil. Namun demikian, jika harga-harga untuk setiap komoditas tidak berada pada harga keseimbangan maka pergerakan harga yang diharapkan menuju pada keseimbangan tersebut tidak terjamin. Oleh karena itu muncul sebuah pertanyaan yang cukup menarik yaitu, kondisi-kondisi apa yang menjamin bahwa harga akan menuju kepada harga keseimbangan? Pertanyaan tersebut merupakan hal yang menarik untuk dibahas dan oleh karena itu tujuan dari tulisan ini adalah mengkaji kondisi-kondisi yang menjamin bahwa harga akan menuju kepada kestabilan keseimbangan pasar.

\section{KAJIAN TEORI}

\section{Sistem Persamaan Differensial, Kestabilan dan Nilai Eigen}

Sebagai awal analisis dalam permasalahan tersebut datas, terlebih dahulu akan dibahas konsep mengenai sistemn persamaan diferensial. Suatu sistem dengan $n$ persamaan diferensial dapat dituliskan sebagai berikut:

$$
\frac{d x_{i}}{d t}=f_{i}\left(x_{1}, x_{2}, \ldots, x_{n}, t\right) \text { dimana } \mathrm{i}=1,2,3 \ldots \mathrm{n}
$$

Bentuk persamaan (1) dikenal dengan sebutan sistem otonom. Jika peubah $t$ tidak muncul secara eksplisit pada fungsi $f_{i}$, maka bentuk (1) dapat dituliskan sebagai:

$$
\frac{d x_{i}}{d t}=f_{i}\left(x_{1}, x_{2}, \ldots ., x_{n}\right) \text { dimana } \mathrm{i}=1,2,3 \ldots \mathrm{n}
$$

Untuk penyederhanaan, bentuk (2) biasa dituliskan dalam notasi vektor, sebagai berikut :

$$
\frac{d x}{d t}=\mathrm{f}(\mathrm{x}) \text { atau } x^{\prime}(t)=\mathrm{f}(\mathrm{x})
$$

dengan $x=\left(x_{1}, x_{2}, \ldots, x_{n}\right)$. Sedangkan persamaan (2) dapat juga berbentuk sistem otonom linear homogen, yang ditulis sebagai berikut :

$$
\left.\frac{d x_{i}}{d t}=a_{i 1} x_{1}+a_{i 2} x_{2}+\ldots .+a_{i n} x_{n}\right)
$$

Persamaan (4) dalam bentuk vektor dan matriks dapat dituliskan sebagai $\dot{x}=A x$ dengan $\dot{x}=\left(\frac{d x_{1}}{d_{t}}, \frac{d x_{2}}{d_{t}}, \ldots, \frac{d x_{n}}{d_{t}}\right)^{T}$.

A menunjukkan matriks berukuran $n \times n$ dengan entri-entrinya $a_{i j}$ dan $i j=1,2, \ldots, n$ sedangkan $x=\dot{x}=\left(\frac{d x_{1}}{d_{t}}, \frac{d x_{2}}{d_{t}}, \ldots, \frac{d x_{n}}{d_{t}}\right)^{T}$

Titik keseimbangan (equilibrium point) akan terjadi jika $\bar{x}=\bar{x}_{1}+\bar{x}_{2}+\ldots .+\bar{x}_{n}$ sebagai suatu keseimbangan dari sistem otonom $x^{\prime}(t)=f(x)$ jika $f_{i}(x)=0$ untuk semua $i$ $=1,2, \ldots, \mathrm{n}$. 
Teorema 1

Titik 0 adalah titik kesetimbangan dari sistem otonom linear $\dot{x}=A x$

Definisi (stabil asimtotik)

Misalkan $\bar{x}$ adalah titik kesetimbangan dari sistem otonom $x^{\prime}(\mathrm{t})=\mathrm{f}(\mathrm{x})$. Titik $\bar{x}$ dikatakan stabil asimtotik jika terdapat $\delta>0, \quad|x(0)-\bar{x}|<\delta$ berimplikasi $\lim _{t \rightarrow \infty}|x(0)-\bar{x}|=0$ dimana, $x_{i}(0)=x_{i}(\mathrm{t})_{\mathrm{t}}=0$. Sedangkan yang terkait dengan vektor eigen dan nilai eigen dapat diuraikan sebagai berikut :

Definisi (vektor eigen dan nilai eigen)

Jika A adalah matriks $n \times n$, maka vektor tak nol $x$ di dalam $R^{n}$ dinamakan vektor eigen dari $A$ jika $A x=\lambda x$ untuk suatu skalar $\lambda$. Skalar dikatakan nilai eigen dari $A \operatorname{dan} x$ dan dikatakan vektor eigen yang bersesuaian dengan $\lambda$. Sedangkan nilai eigen dapat berupa bilangan kompleks yaitu $\lambda=\operatorname{Re}(\lambda)+\operatorname{Im}(\lambda) /$ dimana $\operatorname{Re}(\lambda)$ adalah bagian imajiner dari $\lambda$.

Berdasarkan konsep tersebut teorema yang dapat menjelaskan hubungan antara kestabilan titik keseimbangan pada sistem otonom linear homogen dengan sifat nilai eigen dari matriks yang dibangun adalah sebagai berikut :

Teorema 2

Titik keseimbangan 0 dari sistem otonom linear $\dot{x}=A x$ adalah stabil asimtotik jika dan hanya jika bagian riil dari seluruh nilai eigen matriks $A$ negatif .

Sehubungan dengan Teorema 2 ini yang terkait dengan matriks stabil, dikenal konsep berikut:

Defenisi (matrik stabil)

Suatu matriks yang berukuran $n \times n$ yang bagian riil dari seluruh nilai eigennya negatif disebut sebagai matriks stabil.

Dalam kaitannya dengan kestabilan keseimbangan pasar terdapat matriksmatriks yang memenuhi sifat matrik stabil yang sesuai dengan teori ekonomi, yaitu:

\section{MATRIKS DIAGONAL DOMINAN KOLOM DAN BARIS}

Definisi (diagonal dominan kolom)

Matriks $A=\left[a_{i j}\right]$ berukuran $n \times n$ dikatakan mempunyai diagonal dominan kolom, jika terdapat bilangan positif $d_{1}, d_{2}, \ldots, d_{n}$ sedemikian rupa sehingga $d_{j}\left|a_{i j}\right|>\sum_{i \neq j} d_{i}\left|a_{i j}\right|$ untuk $j=1,2, \ldots, \mathrm{n}$.

Teorema 3

Jika $A=\left[a_{i j}\right]$ berukuran $n \times n$ mempunyai diagonal dominan kolom dengan semua elemen diagonalnya bemilai negatif $\left(a_{i i}<0, v\right.$ i) maka bagian riil dari semua nilai eigennya negatif. 
Berdasarkan Teorema 3 dapat disimpulkan bahwa matriks yang mempunyai diagonal dominan kolom dengan semua elemen diagonalnya negatif adalah matriks stabil.

\section{Teorema 4}

Matrik $A=\left[\mathrm{a}_{\mathrm{ij}}\right]$ berukuran $n \times n$ dan memenuhi $\left|a_{i j}\right|>\sum_{i \neq j}\left|a_{i j}\right|$ untuk $j=1,2, \ldots, \mathrm{n}$ maka $A$ mempunyai diagonal dominan kolom.

Defenisi (diagonal dominan baris)

Matriks $A=\left[\mathrm{a}_{\mathrm{ij}}\right]$ berukuran $n \times n$ dikatakan mempunyai diagonal dominan baris, jika terdapat bilangan positif untuk $d_{1}, d_{2}, \ldots, d_{n}$ sedemikian rupa sehingga $d_{j}\left|a_{i j}\right|>\sum_{i \neq j} d_{i}\left|a_{i j}\right|$ untuk $j=1,2, \ldots, n$.

\section{Teorema 5}

Jika $A=\left[\mathrm{a}_{\mathrm{ij}}\right]$ berukuran $n \times n$ mempunyai diagonal dominan baris dengan semua diagonalnya bernilai negatif $\left(a_{i},<0, v i\right)$ maka bagian riil dari semua nilai eigennya negatif.

Berdasarkan Teorema 5 dapat disimpulkan bahwa matriks yang mempunyai diagonal dominan baris dengan semua elemen diagonalnya negatif adalah matrik stabil.

Teorema 6

Matriks $A=\left[\mathrm{a}_{\mathrm{ij}}\right]$ berukuran $n \times n$ dan memenuhi $\left|a_{i j}\right|>\sum_{j \neq i}\left|a_{i j}\right|$ untuk $i=1,2, \ldots, n$ maka $A$ mempunyai diagonal baris.

\section{Matriks Dengan Elemen Nondiagonal Tak Negatif.}

Matriks dengan elemen nondiagonal tak negatif ini merupakan salah satu karakteristik matriks stabil, yang didukung oleh berbagai teorema berikut :

Teorema 7

Misalkan $A=\left[a_{i j}\right]$ adalah matriks berukuran $n \times n$ sedemikian sehingga $a_{i j} \geq 0$ untuk semua $i \neq j$ maka kondisi-kondisi berikut ekuivalen:

1) Terdapat $x \geq 0$ sedemikian sehingga $A x<0$

2) Terdapat $y \geq 0$ sedemikian sehingga $A^{\top} y<0$

3) Bagian riil dari nilai eigen $A$ adalah negatif

Berdasarkan Teorema 7 dapat disimpulkan bahwa matriks dengan elemen nondiagonal taknegatif yang memenuhi kondisi (1) dan (2) adalah matriks stabil.

\section{FUNGSI HOMOGEN BERDERAJAT-D}

Sifat selanjutnya yang dapat digunakan untuk menelusuri kestabilan keseimbangan berganda adalah fungsi homogen berderajat- $d$. 
Definisi

Fungsi $\left.f\left(x_{1}, x_{2}, \ldots, x_{n}\right)\right)$ dikatakan fungsi homogen berderajat- $d$ jika dan hanya jika memenuhi, $f(\lambda x)=\lambda^{d} f(x) ; \lambda>0$ dimana $x=\left(\mathrm{x}_{1}, \mathrm{x}_{2}, \ldots, \mathrm{x}_{\mathrm{n}}\right)$. Sehingga apabila $f_{i}(p)$ adalah fungsi homogen berderajat nol maka berlaku $f_{i}(\lambda p)=f_{i}(p) ; \lambda>0$ dengan $i=$ $1,2, . ., n$. Kondisi ini dalam ilmu ekonomi sering disebutan dengan sifat homogenitas (homogineity). Sifat homogenitas pada fungsi kelebihan permintaan bagi komoditas ke-i memiliki makna bahwa $f_{i}(p)$ adalah fungsi homogen berderajat nol.

\section{Teorema 8}

Misalkan $f\left(x_{1}, x_{2}, \ldots, x_{n}\right)$ adaiah fungsi homogen berderajat- $d$, maka berlaku konsep sebagai berikut:

$$
x_{1} \cdot \frac{d f(x)}{d x_{1}}+x_{2} \cdot \frac{d f(x)}{d x_{2}}+\ldots+x_{n} \cdot \frac{d f(x)}{d x_{n}}=d f(x)
$$

dimana $x=\left(x_{1}, x_{2}, \ldots, x_{n}\right)$.

Berdasarkan sifat homogen berderajat nol ini maka dengan memilih $\lambda=\frac{1}{x_{n}}$; $f\left(x_{1}, x_{2}, \ldots, x_{n}\right)$ dapat dinyatakan sebagai:

$$
f\left(\frac{x_{1}}{x_{n}}+\frac{x_{2}}{x_{n}}+, \ldots,+x_{n} \cdot \frac{x_{n-1}}{x_{n}}, 1\right)
$$

\section{PEMBAHASAN}

\section{Keseimbangan Pasar Berganda}

Misalkan pasar berganda dengan $n$ barang (komoditas) yaitu $x=\left(x_{1}, x_{2}, \ldots, x_{n}\right)$ dengan masing-masing harga $p=\left(p_{1}, p_{2, \ldots,} p_{n}\right)$ dimana; $i=1,2, \ldots$, n. Jika fungsi permintaan bagi komoditas ke-i disimbolkan $D_{i}(p)$ dan fungsi penawaran disimbolkan dengan $S_{i}(p)$, sedangkan kelebihan permintaan (excess demand) yang merupakan selisih antara jumlah permintaan dengan jumlah penawaran disimbolkan dengan $f_{i}(p)$, maka kesetimbangan pada komoditas ke-i akan tercapai jika dan hanya jika terdapat vektor harga $\bar{p}$ sedemikian sehingga:

$$
D_{i}(\bar{p})=S_{i}(\bar{p})
$$

$\bar{p}$ disebut vektor harga keseimbangan. Keseimbangan komoditas ke-i juga dapat dituliskan sebagai:

$$
f_{i}(\bar{p})=D_{i}(\bar{p})-S_{i}(\bar{p})=0
$$

Keseimbangan secara keseluruhan tercapai bila kondisi keseimbangan pada persamaaan (7) diatas berlaku untuk semua komoditas ke-i dengan $i=1,2, \ldots, n$. Kondisi kesetimbangan tersebut ditulis: 


$$
f(\bar{p})=0
$$

\section{MODEL PASAR BERGANDA DINAMIK SAMUELSON}

Model pasar berganda dinamik adalah pasar berganda yang mempertimbangkan faktor variabel waktu dan untuk memodelkan pergerakan harga dalam suatu pasar. Samuelson memanfaatkan suatu fenomena yang terjadi dari kenyataan yang ada bahwa perubahan harga akan sangat bergantung pada perubahan kelebihan permintan artinya harga melakukan penyesuaian terhadap kelebihan permintaan. Pada suatu tingkat harga tertentu, misalkan $p$, jumlah permintaan lebih besar dari jumlah penawaran, $D_{i}(p)>S_{i}(p)$ atau $f(p)>0$, maka harga akan bergerak naik dan sebaliknya jika jumlah permintaan lebih kecil dari jumlah penawaran, $D_{i}(p)<S_{i}(p)$ atau $f(p)<0$, harga akan bergerak turun. Sehingga untuk setiap komoditas Samuelson menuliskannya sebagai suatu sistem persamaan differensial yaitu:

$$
\begin{gathered}
\frac{d p_{i}(t)}{d t}=k_{i} f_{i}\left[p_{1}(t), p_{2}(t), \ldots, p_{n}(t)\right] \\
i=1,2, \ldots, n
\end{gathered}
$$

Dimana :

(i) $\quad k_{i}$ adalah kecepatan penyesuaian (speed of adjustment) dari komoditas ke-i, $k_{i}>0$;

(ii) $\quad f_{i}(p)=f_{i}\left[p 1(t), p_{2}(t), \ldots, p_{n}(t)\right]$ bersifat otonom dan $t$ tidak muncul secara eksplisit serta terturunkan terhadap $p_{j}$; untuk semua $j=1,2, \ldots, n$.

(iii) $\quad P_{i}(t)$ adalah harga komoditas ke-i $p_{i}(t)>0$ untuk semua $t \geq 0$.

Persamaan (9) disebut sistem penyesuaian harga dinamik Samuelson. Dengan pemilihan yang tepat terhadap ukuran setiap unit-unit pada setiap komoditas, dapat diasumsikan bahwa $k_{i}=1$ sehingga dengan notasi vektor dapat dituliskan sebagai berikut :

$$
\frac{d p(t)}{d t}=f[p(t)]
$$

Implikasi dari persamaan (10) ini yang berbentuk sistem otonom linear homogen yang jika diambil aproksimasi linear Taylor dari $f_{i}(p)$ pada titik-titik disekitar $\bar{p}=\left(\bar{p}_{1}, \bar{p}_{2}, \ldots, \bar{p}_{n}\right)$, yaitu:

$$
f_{i}(p)=f_{i}(\bar{p})+\sum_{j=1}^{n} \frac{d f_{i}(\bar{p})}{d p_{j}}\left[p_{j}(t)-\bar{p}_{j}\right]
$$

Karena $f_{i}(p)=0$ untuk semua $i=1,2, \ldots . . n$; maka:

$$
f_{i}(p)=\sum_{j=1}^{n} \frac{d f_{i}(\bar{p})}{d p_{j}}\left[p_{j}(t)-\bar{p}_{j}\right]
$$


Sehingga persamaaan (10) dapat berubah menjadi :

$$
\frac{d p_{i}(t)}{d t}=\sum_{j=1}^{n} a_{i j}\left[p_{j}(t)-\bar{p}_{j}\right]
$$

Dimana $a_{i j}=\frac{d f_{i}(\bar{p})}{d p_{j}}$ dan $a_{i j}$ merupakan suatu konstanta. Notasi vektor dari persamaan (13) dapat dituliskan sebagai:

$$
\frac{d p_{i}(t)}{d t}=\dot{p}=A[p(t)-\bar{p}]
$$

dimana, $A$ merupakan matriks berukuran $n \times n$ dengan entri-entrinya adalah $a_{i j}$ dengan $i, j=1,2, \ldots, n$.

Dalam bentuk penyederhanaan proses tersebut dapat dimisalkan bahwa $q_{j}=p_{j}(t)-\bar{p}_{j}$ dan jika diselesaikan didperoleh nilai sebagai berikut:

$$
\frac{d q_{j}(t)}{d t}=\frac{d}{d t}\left[p_{j}(t)-\bar{p}\right]=\frac{d p_{j}(t)}{d t}
$$

dan pada akhirnya persarnaan (14) juga dapat dituliskan

$$
\dot{q}=A q
$$

Persamaan (16) ini mempunyai implikasi dalam bentuk matriks sebagai berikut :

$$
\left[\begin{array}{c}
\frac{d q_{1}(t)}{d t} \\
\frac{d q_{1}(t)}{d t} \\
\vdots \\
\frac{d q_{1}(t)}{d t}
\end{array}\right]=\left[\begin{array}{cccc}
a_{11} & a_{12} & \ldots & a_{1 n} \\
a_{21} & a_{22} & \ldots & a_{2 n} \\
\vdots & \vdots & \ddots & \vdots \\
a_{n 1} & a_{n 2} & \ldots & a_{n n}
\end{array}\right]\left[\begin{array}{c}
q_{1} \\
q_{2} \\
\vdots \\
q_{n}
\end{array}\right]
$$

Implikasi dari persamaan (15) ini adalah merupakan system penyesuaian harga secara dimanik menurut Samuelson yang diaproksimasi dan persamaan tersebut juga membentuk suatu system otonom linear homogen.

\section{KESTABILAN KESEIMBANGAN PASAR BERGANDA}

Kestabilan keseimbangan pasar berganda yang terdiri dari $n$ komoditas, dimisalkan $\bar{p}=\left(\bar{p}_{1}, \bar{p}_{2}, \ldots, \bar{p}_{n}\right)$, dijamin apabila berlaku:

$$
\lim _{t \rightarrow \infty} p_{i}(t)=\bar{p}_{i} ; \text { untuk } \forall \mathrm{i}=1,2, \ldots, \mathrm{n}
$$

Untuk menelusuri kestabilan keseimbangan pada pasar berganda dapat memanfaatkan sistem penyesuaian harga dinamik Samuelsom yang diaproksimasi pada model persaman (15). Teorema yang mendukung model tersebut adalah sebagai berikut : 
Teorema 9

Jika matrik $A$ pada sistem penyesuaian harga dinamik Samuelson yang diaproksimasi merupakan matriks stabil maka kestabilan keseimbangan pasar berganda tercapai.

Sebagai pembuktian dapat ditelusuri hal berikut ini:

1. Sistem penyesuaian harga dinamik Samuelson yang diaproksimasi, yaitu:

$$
\dot{q}=A q
$$

Dengan A adalah matrik berukuran $n \times n$ dengan elemennya adalah:

$$
a_{i j}=\frac{d f_{i}(\bar{p})}{d p_{i}} ; \forall i ; j=1,2, \ldots n
$$

Karena $A$ adalah matrik stabil dan dari Teorema 2 diperoleh bahwa titik keseimbangan $q=0$ adalah stabil asimtotik, maka terdapat kondisi $\delta>0$, $|q(0)-0|<\delta$, hal berimplikasi bahwa $\lim _{t \rightarrow \infty}|q(t)-0|=0$

$$
\begin{aligned}
& \lim _{t \rightarrow \infty}|\mathbf{q}(t)-0| \\
& =\lim _{t \rightarrow \infty}|\mathbf{q}(t)| \\
& =\lim _{t \rightarrow \infty} \sqrt{q_{1}(t)^{2}+q_{2}(t)^{2}+\ldots+q_{n}(t)^{2}} \\
& =\lim _{t \rightarrow \infty} \sqrt{\left(p_{1}(t)-\bar{p}_{1}\right)^{2}+\left(p_{2}(t)-\bar{p}_{2}\right)^{2}+\ldots+\left(p_{n}(t)-\bar{p}_{n}\right)^{2}} \\
& =0
\end{aligned}
$$

Kondisi persamaan (19) ini akan terjadi jika dan hanya jika berlaku:

$$
\lim _{t \rightarrow \infty}\left(p_{i}(t)-\bar{p}_{i}\right)=0 ; \forall \mathrm{i}=1,2, \ldots, \mathrm{n} .
$$

Impilkasi dari kondisi tersebut adalah:

$$
\lim _{t \rightarrow \infty} p_{i}(t)=\bar{p}_{i}
$$

Sehingga kestabilan kesetimbangan pasar berganda tercapai.

\section{KESIMPULAN}

Matriks yang dibangkitkan dari sistem penyesuaian harga Samuelson dapat dimanfaatkan untuk menentukan kondisi yang menjamin kestabilan keseimbangan pasar berganda dengan $n$ komoditas. Salah satu kondisi yang menjamin keseimbangan pasar adalah adanya sifat bahwa setiap komoditas yang ada dalam pasar berganda merupakan barang normal dan setiap permintaan pada setiap komoditas kurang dipengaruhi oleh perubahan harga komoditas lain, sebaliknya sangat dipengaruhi oleh perubahan harga pada komoditas itu sendiri. 


\section{DAFTAR PUSTAKA}

Arrow, K.J, Block, H.D and Hurwichz, L, 1959, On the Stability of the Competitive Equilibrium II. Econometrica 27:89-109.

Chiang, A.C, 1984, Fundamental Methods of Mathematical Economics. 3th Edition. McGrawhill International Book Company, Singapore.

Hahn, F.N, 1958, Gross Substitutes and Dynamic Stability of General Equilibrium, Econometrica 26:169-170.

Henderson, J.M., Quandt R.C, 1982, Microeconomic Theory A Mathematical Approach 3th Edition, Mc-Graw Hill International Book Company. Singapore.

Takayama, Akira, 1984. Mathematical Economics, $2^{\text {nd }}$ Edition, Cambridge University Press, Cambridge.

Tu, Pierre, N.V, 1984, Dynamical System. An Introduction with Application in Economics and Biology, Spriger-Verlag. Berlin. 